\title{
Evolution of multiple sex-chromosomes associated with dynamic genome reshuffling in Leptidea wood-white butterflies
}

\author{
Atsuo Yoshido $\mathbb{1}^{1} \cdot$ Jindra Šíchová ${ }^{1}$ Kristýna Pospíšilová1,2 $\cdot$ Petr Nguyen $\mathbb{1}^{1,2} \cdot$ Anna Voleníková $\mathbb{C}^{1,2} \cdot$ Jan Šafáŕ ${ }^{3}$. \\ Jan Provazník $\mathbb{B}^{1,5} \cdot$ Roger Vila $\mathbb{1}^{4} \cdot$ František Marec $\mathbb{D}^{1}$
}

Received: 11 March 2020 / Revised: 21 May 2020 / Accepted: 21 May 2020 / Published online: 9 June 2020

(c) The Author(s) 2020. This article is published with open access

\begin{abstract}
Sex-chromosome systems tend to be highly conserved and knowledge about their evolution typically comes from macroevolutionary inference. Rapidly evolving complex sex-chromosome systems represent a rare opportunity to study the mechanisms of sex-chromosome evolution at unprecedented resolution. Three cryptic species of wood-white butterfliesLeptidea juvernica, $L$. sinapis and $L$. reali-have each a unique set of multiple sex-chromosomes with 3-4 W and 3-4 Z chromosomes. Using a transcriptome-based microarray for comparative genomic hybridisation (CGH) and a library of bacterial artificial chromosome (BAC) clones, both developed in L. juvernica, we identified Z-linked Leptidea orthologs of Bombyx mori genes and mapped them by fluorescence in situ hybridisation (FISH) with BAC probes on multiple $\mathrm{Z}$ chromosomes. In all three species, we determined synteny blocks of autosomal origin and reconstructed the evolution of multiple sex-chromosomes. In addition, we identified W homologues of Z-linked orthologs and characterised their molecular differentiation. Our results suggest that the multiple sex-chromosome system evolved in a common ancestor as a result of dynamic genome reshuffling through repeated rearrangements between the sex chromosomes and autosomes, including translocations, fusions and fissions. Thus, the initial formation of neo-sex chromosomes could not have played a role in reproductive isolation between these Leptidea species. However, the subsequent species-specific fissions of several neo-sex chromosomes could have contributed to their reproductive isolation. Then, significantly increased numbers of Z-linked genes and independent neo-W chromosome degeneration could accelerate the accumulation of genetic incompatibilities between populations and promote their divergence resulting in speciation.
\end{abstract}

Associate Editor: Ben Evans

Supplementary information The online version of this article (https:// doi.org/10.1038/s41437-020-0325-9) contains supplementary material, which is available to authorised users.

František Marec

marec@entu.cas.cz

1 Biology Centre of the Czech Academy of Sciences, Institute of Entomology, Branišovská 31, 37005 České Budějovice, Czech Republic

2 Faculty of Science, University of South Bohemia, Branišovská 1760, 37005 České Budějovice, Czech Republic

3 Institute of Experimental Botany of the Czech Academy of Sciences, Centre of the Region Hana for Biotechnological and Agricultural Research, Šlechtitelů 31, 77900 Olomouc, Czech Republic

4 Institut de Biologia Evolutiva (CSIC-UPF), Pg. Marítim de la Barceloneta 37, 08003 Barcelona, Spain

5 Present address: Genomics Core Facility, European Molecular Biology Laboratory, Heidelberg, Germany

\section{Introduction}

Sex chromosomes (XY/XX in male heterogamety and WZ/ $\mathrm{ZZ}$ in female heterogamety) are known to play an important role in fundamental evolutionary processes, such as sex determination, inheritance of sex-specific traits, adaptation and speciation. A large contribution of the $\mathrm{X}$ chromosome to reproductive isolation (the so-called 'large X-effect') is well established, especially in Drosophila species (Presgraves 2008). In some organisms with female heterogamety, Z-linked genes or traits also contribute significantly to speciation and adaptation, referred to as the 'large Z-effect' (Qvarnström and Bailey 2009). Sex-limited Y or $\mathrm{W}$ chromosomes are frequently associated with sex-specific traits. For example, in some organisms, these chromosomes carry primary sex-determining signals (Bachtrog et al. 2014). In addition, several studies suggest that the $Y$ chromosome plays a role in reproductive isolation of some organisms (Sweigart 2010; Campbell et al. 2012). The 
chicken $\mathrm{W}$ chromosome affects female fertility traits as well (Moghadam et al. 2012). Due to these properties, turnover of sex chromosomes by rearrangements with autosomes may facilitate adaptation and promote speciation (Kitano et al. 2009; Kitano and Peichel 2012; Nguyen et al. 2013; Graves 2016). Moreover, the sex chromosomes themselves are the source of intralocus and intragenomic conflicts that may even cause the turnover of sex chromosomes (Mank et al. 2014). Neo-sex chromosomes and multiple sex-chromosomes, originating from fusions and/or translocations between sex chromosomes and autosomes, occur in species with both XY and WZ systems (Marec et al. 2010; Pennell et al. 2015). Exceptionally, repeated sex chromosomeautosome translocations can generate even more complex multiple sex-chromosomes like $\mathrm{X}_{1-5} \mathrm{Y}_{1-5} / \mathrm{X}_{1-5} \mathrm{X}_{1-5}$ in platypus (Rens et al. 2004). Thus, the evolution and molecular differentiation of sex chromosomes are among the most intriguing questions of evolutionary genetics.

Accumulating evidence suggests that sex chromosomes of moths and butterflies (Lepidoptera), the largest group of animals with holokinetic chromosomes and female heterogamety, also play a disproportionate role in speciation compared with autosomes. In a number of lepidopteran species, Z-linked genes significantly contribute to the formation of prezygotic and/or postzygotic reproductive barriers between different strains and closely related species (Sperling 1994; Naisbit et al. 2002; Presgraves 2002; Dopman et al. 2005; Kost et al. 2016). In addition, recent results suggest that a sex-linked inversion promotes divergence and facilitates speciation by suppressing recombination between $\mathrm{Z}$ chromosomes of two strains of the European corn borer moth, Ostrinia nubilalis (Wadsworth et al. 2015). Besides the common WZ/ZZ (\$/ð) sex chromosomes, $\mathrm{WZ}_{1} \mathrm{Z}_{2}$ and $\mathrm{W}_{1} \mathrm{~W}_{2} \mathrm{Z}$ multiple sex-chromosome systems were found only in several distantly related lepidopteran taxa (Traut et al. 2007; Marec et al. 2010; Sahara et al. 2012). However, neo-sex chromosomes formed by fusion of both $\mathrm{W}$ and $\mathrm{Z}$ chromosomes with autosomes are much more common in Lepidoptera than previously thought (Nguyen et al. 2013; Mongue et al. 2017; Carabajal Paladino et al. 2019). Transfer of the whole set of autosomal genes under Z-linkage, as in multiple or neo-sex chromosomes, can greatly contribute to ecological specialisation, reproductive isolation and speciation in Lepidoptera (Yoshido et al. 2011a; Nguyen et al. 2013; Carabajal Paladino et al. 2019). This is demonstrated by the neo-W chromosome of the African queen butterfly, Danaus chrysippus, which drives speciation across the hybrid zone by linking the colour pattern and male killing caused by an endosymbiotic bacterium, Spiroplasma ixodeti (Smith et al. 2016; Traut et al. 2017).

Wood-white butterflies of the genus Leptidea (Pieridae) constitute an excellent model for studying the role of chromosome rearrangements in speciation. Especially three species with mainly Western Palaearctic distribution$L$. juvernica, $L$. sinapis and $L$. reali-represent one of the most striking examples of cryptic diversity in Eurasian butterflies (Dincă et al. 2011). This triplet of species has evolved strong pre-mating reproductive barriers in their sympatric and allopatric populations (Friberg et al. 2008; Dincă et al. 2013). In addition, chromosome numbers vary greatly between and even within the species due to multiple chromosome fusions and fissions (Dincă et al. 2011; Lukhtanov et al. 2011, 2018; Šíchová et al. 2015). Genome sequencing showed that the genome assembly of $L$. sinapis $(643 \mathrm{Mb})$ is one of the largest in Lepidoptera studied so far, and variations in genome size between and within Leptidea species have been documented (Talla et al. 2017).

Previous studies showed that each of the four Leptidea species examined have a unique, species-specific and complex system of multiple sex-chromosomes: $\mathrm{W}_{1-3} \mathrm{Z}_{1-4} /$ $\mathrm{Z}_{1-4} \mathrm{Z}_{1-4}$ in $L$. juvernica $\left(\% / /^{\star}\right), \mathrm{W}_{1-3} \mathrm{Z}_{1-3} / \mathrm{Z}_{1-3} \mathrm{Z}_{1-3}$ in L. sinapis, $\mathrm{W}_{1-4} \mathrm{Z}_{1-4} / \mathrm{Z}_{1-4} \mathrm{Z}_{1-4}$ in $L$. reali and $\mathrm{W}_{1-3} \mathrm{Z}_{1-6}$ $/ Z_{1-6} Z_{1-6}$ in L. amurensis (Š́́chová et al. 2015, 2016). Despite fluctuating chromosome numbers, even between siblings of individual species, the sex-chromosome systems seem stable in each species. Thus, these closely related species provide a unique opportunity to address the role of sex-chromosome rearrangements in the formation of reproductive barriers between their populations. However, little is known about the composition and origin of these multiple sex-chromosomes, because in such complex systems it is difficult to identify all sex chromosomes simply from genome assembly.

In this study, we cytogenetically identified $\mathrm{Z}$ chromosomes in three cryptic Leptidea species (L. juvernica, $L$. sinapis and $L$. reali) and reconstructed the evolution of their multiple sex-chromosome systems by comparative mapping of sex-linked genes. For this purpose we have developed a couple of genomic tools in $L$. juvernica, namely a female transcriptome-based microarray for comparative genomic hybridisation $(\mathrm{CGH})$ and a bacterial artificial chromosome (BAC) library from females. BAC probes containing Leptidea orthologs of Bombyx mori genes identified all $\mathrm{Z}$ chromosomes in three Leptidea species. Furthermore, we analysed several BAC clones derived from the $\mathrm{W}$ chromosomes of $L$. juvernica, which allowed us to identify femalespecific sequences and $\mathrm{W}$-linked genes of autosomal origin.

\section{Materials and methods}

\section{Specimens}

Adult specimens of Leptidea juvernica and L. sinapis were collected in several localities in the Czech Republic whereas 
L. reali was collected in the Montseny area near Barcelona, Spain. The taxonomic determination of specimens used was verified by morphometric analysis of their genitalia and sequencing of a mitochondrial gene, cytochrome c oxidase subunit 1, as described in Šíchová et al. (2015). Fertilised females were individually kept in plastic containers to lay eggs. Hatched larvae of all three species were reared on one of their host plants, Lotus corniculatus, at room temperature and a natural day/night regime.

\section{RNA sequencing and female transcriptome assembly in Leptidea juvernica}

Total RNA was extracted from a homogenised female larva of $L$. juvernica (gut removed) using an RNA Blue reagent (Top-Bio, Prague, Czech Republic) according to the manufacturer's protocol. An mRNA-seq library was constructed and sequenced using the Illumina HiSeq2000 platform by EMBL Genomics Core Facility (Heidelberg, Germany). Generated raw 100-bp paired-end reads were checked by FastQC (Andrews 2010) and trimmed and quality filtered by Trimmomatic version 0.30 ('LEADING:5 TRAILING:5 SLIDINGWINDOW:4:20'; Bolger et al. 2014). Transcriptome sequence was then assembled de novo by SOAPdenovo-trans-127mer with multiple odd k-mer sizes ranging from 21 to 81 (Xie et al. 2014) and Trinity (Haas et al. 2013). The resulting assemblies were merged and redundancy was removed by the EvidentialGene pipeline (Gilbert 2013).

\section{Array-CGH analysis in Leptidea juvernica}

To identify sex-linked genes in L. juvernica, microarraybased comparative genomic hybridisation (array-CGH) was performed according to the method described in Baker and Wilkinson (2010) (for details, see Supplementary Methods). Briefly, we searched for Leptidea orthologs of Bombyx mori genes in the EvidentialGene output using HaMStR (Ebersberger et al. 2009). The Leptidea orthologs were used to design 60-mer oligonucleotide probes for custom-made microarray slides using Agilent Technologies eArray design wizard. DNA digestion, labelling and array-CGH were performed by GenLabs (Prague, Czech Republic) following a protocol for Agilent oligonucleotide array-based CGH for genomic DNA analysis.

\section{Construction of BAC library in Leptidea juvernica females}

A BAC library was constructed from female pupae of $L$. juvernica. The procedure followed the modified protocol described previously (Šafár et al. 2010). Briefly, high molecular weight DNA isolated from female pupae and embedded in agarose plugs was partially digested with restriction enzyme HindIII. The digested DNA was separated by pulsed field gel electrophoresis (two size-selection steps); $100-300-\mathrm{kb}$ fragments were then isolated from the gel and ligated into a dephosphorylated vector pAGIBAC5. Recombinant BACs were transformed into $E$. coli strain MegaX DH10B T1 (Invitrogen, Carlsbad, CA, USA) by electroporation. In total, 36,864 clones were picked by an automatic robotic station Q-BOT, ordered in 384-well microtiter plates, and stored at $-80^{\circ} \mathrm{C}$. The average insert size in BAC clones was a $125 \mathrm{~kb}$. A master copy of the BAC library, named LjufhA, is stored at the Centre of Plant Structural and Functional Genomics in Olomouc, Czech Republic. The master copy was used for preparation of two working copies. Subsequently, clones from a working copy of the LjufhA BAC library were used to prepare 3 DNA pools. Briefly, a liquid handling system Biomek NX (Beckman Coulter, Brea, CA, USA) was used for pooling 384 clones of each plate ('plate pool'), for pooling rows from 384-well plates ('row pool'), and for pooling columns from 384-well plates ('column pool'). DNA from pooled clones was isolated by standard alkaline lysis and ordered in 96-well microtiter plates for further PCR screening.

\section{BAC screening for FISH mapping}

Sequence information of Leptidea orthologs of B. mori genes was obtained from the transcriptome assembly of L. juvernica females. By blast searching gene models in KAIKObase (http://sgp.dna.affrc.go.jp/KAIKObase/) against the L. juvernica transcriptome, selected Leptidea orthologs of $B$. mori genes were identified. We then designed primer sets to identify BAC clones containing the respective Leptidea orthologs from the BAC library (Supplementary Table S1). For BAC screening, we used a 3-step PCR-based screening method as described previously (Yasukochi 2002; Yoshido et al. 2015). Each reaction mixture was composed of $1.0 \mu \mathrm{l}$ of template BAC-DNA pools, 10 pmol of each primer, $0.25 \mathrm{U}$ of OneTaq DNA Polymerase and $2.0 \mu \mathrm{l}$ of 5x OneTaq Standard Reaction Buffer (New England BioLabs, Ipswich, MA, USA). PCR amplifications were conducted under the following conditions: initial denaturation for $5 \mathrm{~min}$ at $94^{\circ} \mathrm{C}$, 40 cycles of denaturation for $30 \mathrm{~s}$ at $94^{\circ} \mathrm{C}$, annealing for $30 \mathrm{~s}$ at $55-60^{\circ} \mathrm{C}$, elongation for $30-180 \mathrm{~s}$ at $68^{\circ} \mathrm{C}$ and final elongation for $1 \mathrm{~min}$ at $72^{\circ} \mathrm{C}$. PCR products were loaded on 1.0-2.0\% agarose gel in TAE buffer. Gels were stained with ethidium bromide and photographed under UV light.

\section{BAC-FISH mapping}

All required procedures are described in detail in Supplementary Methods. Spread preparations of meiotic chromosomes were obtained from gonads (ovaries and testes) and 
mitotic chromosomes from wing imaginal discs of the last instar larvae as described in Šíchová et al. (2015) and Yoshido et al. (2015). For mapping of gene orthologs on a particular chromosome, several rounds of two-colour BACFISH were carried out following the procedure and reprobing protocol described in Yoshido et al. (2015). Extracted BAC-DNAs were labelled by nick translation using a mixture of DNase I and DNA polymerase I with either aminoallyl-dUTP-Cy3 or fluorescein-12-dUTP and BAC probes hybridised to chromosomes using the BACFISH mapping protocol (Yoshido et al. 2015).

\section{Analysis of BAC clones derived from $\mathbf{W}$ chromosomes and $W$ homologues of Z-linked orthologs}

To find BAC clones derived from $\mathrm{W}$ chromosomes in $L$. juvernica, we screened the BAC library using FISH-based screening (Supplementary Fig. S1). Extracted BAC-DNAs of two clones derived from $\mathrm{W}$ chromosomes of $L$. juvernica (see 'Results') were digested with restriction enzyme HindIII, and several digested DNA fragments (700-5000 bp) were sub-cloned into pJET1.2/blunt Cloning Vector using the CloneJET PCR Cloning Kit (Thermo Fisher Scientific, Waltham, MA, USA). The plasmids obtained were transformed into Escherichia coli DH5 $\alpha$ strain. Plasmid DNAs were extracted using the NucleoSpin Plasmid kit (Macherey-Nagel, Düren, Germany) and sequenced using universal primers. Analysis of W homologues of Z-linked orthologs of the Uch $5 l$ and Gst 8 genes was performed by PCR and sequencing as described in Supplementary Methods.

\section{Quantitative real-time PCR (qPCR)}

To compare a relative gene dose of Leptidea orthologs between females and males, we performed quantitative realtime PCR (qPCR) using gDNAs as templates according to the method described in Nguyen et al. (2013) with slight modifications. For qPCR, gDNAs were extracted separately from three females and three males of $L$. juvernica, $L$. sinapis, and $L$. reali by standard phenol-chloroform procedure. Target and reference genes were analysed simultaneously in three different specimens for each sex. The Leptidea ortholog of the B. mori RpS5 gene was used as an autosomal reference gene. Primer sets for respective target and reference genes are listed in Supplementary Table S1 (asterisk) or Table S5. The qPCR was performed using a reaction mixture composed of $0.5-20 \mathrm{ng}$ of template gDNA, 0.5 pmol of each primer and $5 \mu l$ of Xceed qPCR SG $2 \times$ Mix Lo-Rox (Institute of Applied Biotechnologies, Prague, Czech Republic). To calculate the amplification efficiency $(E), 4$ points of 4 times dilution series were used. The obtained data were processed using CFX Manager Software (Bio-Rad). The PCR reaction was carried out using the C1000 Thermal cycler CFX96 Real-Time System (Bio-Rad, Hercules, CA, USA). The female-to-male relative dose ratio of the target gene was determined by comparison with the autosomal reference gene using a formula of Pfaffl (2001) and statistically analysed by unpaired two-tailed $t$ test for unequal variances.

\section{Results}

\section{Array-CGH in Leptidea juvernica}

To identify candidate orthologs located on $L$. juvernica $\mathrm{Z}$ chromosomes, we carried out array-CGH (Fig. 1). After filtering, L. juvernica $\log _{2}$ ratio values of male-to-female signal intensities were obtained for 4252 orthologs. The values averaged across four replicas clearly showed a bimodal distribution with an autosomal peak centred at -0.1 (Fig. 1a). Using a cut-off value of 0.5 , we identified 454 putative Z-linked orthologs. Chromosomal location of their B. mori counterparts revealed that the identified $L$. juvernica Z-linked orthologs contain vast majority of genes assigned to B. mori Z-chromosome (chr. 1) and are further enriched on B. mori chr. 7, chr. 8, chr. 11, chr. 17 and chr. 24 (Fig. 1b).

\section{BAC-FISH mapping of $Z_{1}$ chromosome}

We identified 19 BAC clones containing Leptidea orthologs of 17 B. mori Z-linked genes (Supplementary Table S1) and mapped them to $L$. juvernica chromosomes. Fourteen out of nineteen prepared BAC probes mapped to a single bivalent in L. juvernica males (Fig. 2a and Supplementary Table S1). This bivalent is evidently a Z-chromosome pair, since two representative probes out of these 14 , BAC $62 \mathrm{~N} 7$ and 91P9, containing orthologs of Masc and ket genes, respectively, mapped both to the same element of the sexchromosome multivalent in L. juvernica females (Fig. 5a). We named this element as $Z_{1}$ chromosome. One of the probes, BAC $9 \mathrm{~J} 14$ containing the Leptidea ortholog of B. mori Prm, hybridised not only to $\mathrm{Z}_{1}$ but also to one autosomal bivalent, suggesting duplication of the $Z_{1}$ region carrying this gene (Supplementary Fig. S2a). The remaining four probes, BAC 91C3 containing the Pgd ortholog, 96D19, 66L7 and $62 \mathrm{O} 17$ containing each different sizefragment of the Tpi ortholog (Supplementary Table S1), mapped to autosomal bivalents in L. juvernica females (Supplementary Text 1 and Supplementary Fig. S2b, c). These results suggest that the orthologs of these two B. mori Z-linked genes, $P g d$ and $T p i$, are not Z-linked in L. juvernica and the Tpi ortholog is not a single copy gene 


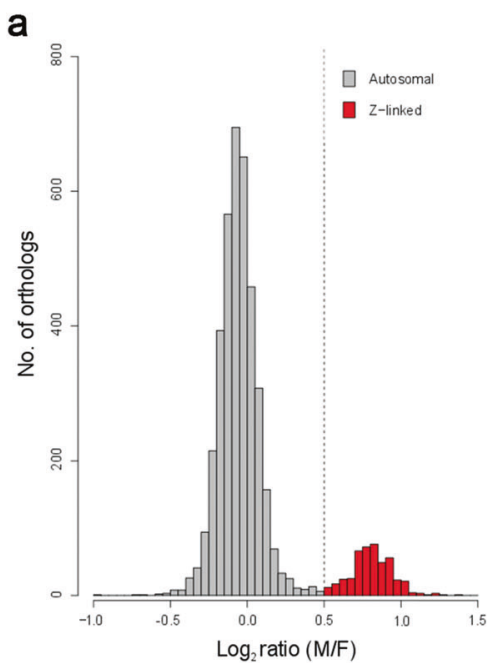

Fig. 1 Array-CGH in Leptidea juvernica. a Distribution of CGH $\log _{2}$ ratio of male-to-female signal intensities. The peak centred at -0.1 (grey) corresponds to putative autosomal orthologs while bins with values $>0.5$ (red) forming the smaller peak comprise putative Z-linked

b

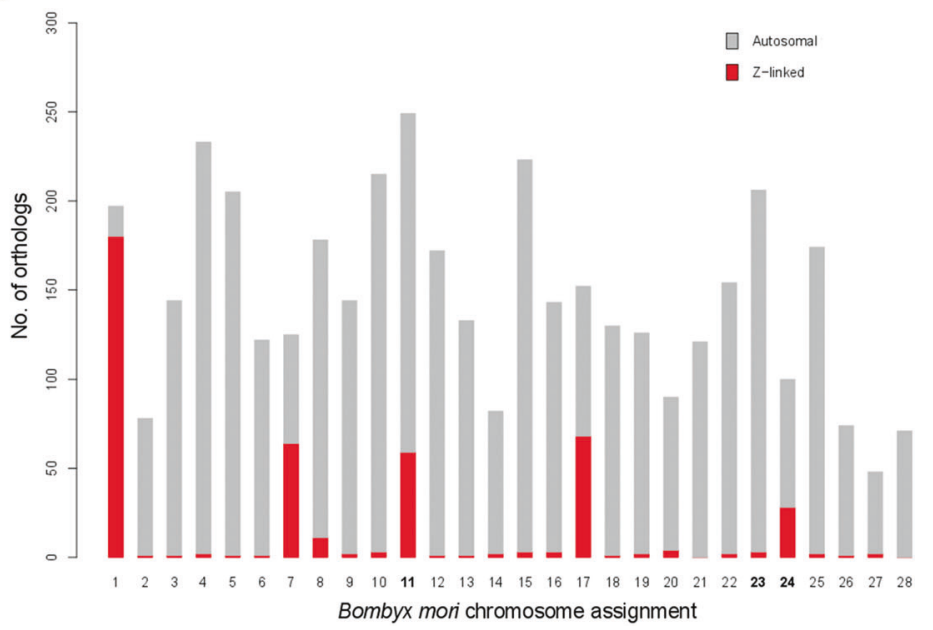

orthologs. A total of 4252 orthologs are presented. b Autosomal (grey) and sex-linked (red) L. juvernica orthologs and their chromosome assignment in the Bombyx mori reference genome; B. mori chromosomes of fusion origin are in bold. in the genome. Gene movement out of the L. juvernica $\mathrm{Z}_{1}$ chromosome, such as $P g d$ translocation and Tpi translocation followed by duplication, is better documented by results of array-CGH, which showed that only 17 of the 197 tested orthologs (i.e., 8.6\%) of B. mori Z-linked genes are autosomal (Fig. 1b). Regarding $P g d$, the autosomal location of this ortholog is fully consistent with a $-0.0125 \mathrm{CGH}$ $\log _{2}$ ratio of the male-to-female signal intensities. The orthologs of Prm and Tpi were not included in the microarray.

FISH mapping of 14 BAC probes containing Leptidea orthologs of $B$. mori Z-linked genes showed that the probes did not cover the whole length of the $L$. juvernica $\mathrm{Z}_{1}$ chromosome (Fig. 2a, asterisk). Thus, we tested BAC clones containing putative sex-linked Leptidea orthologs of B. mori autosomal genes identified by array-CGH (Fig. 1b). Three BAC probes, 19D3, 94M23 and 92J7, containing orthologs of $B$. mori chr. 17 genes, also mapped to $Z_{1}$ in L. juvernica males (Fig. 2b). However, three BAC probes, 66E20, 65E15 and 93F8, containing putative autosomal orthologs of B. mori chr. 17 genes, mapped to two autosomes in L. juvernica males (Fig. 2, underlined genes and Supplementary Fig. S3a). These results suggest that the $\mathrm{Z}_{1}$ chromosome of $L$. juvernica consists of Leptidea orthologs of most of the B. mori Z-linked genes and part of the B. mori chr. 17 genes.

To verify the conservation of the $\mathrm{Z}_{1}$ chromosome in Leptidea, $\mathrm{Z}_{1}$-derived $\mathrm{BAC}$ probes were cross-hybridised to chromosomes of two other species, $L$. sinapis and $L$. reali. In $L$. sinapis, $17 \mathrm{Z}_{1}$-derived $\mathrm{BAC}$ probes mapped to a single bivalent in males and even in the same order as in the $\mathrm{Z}_{1}$ chromosome of $L$. juvernica (Fig. 2c, d). Three representative BAC probes out of these 17, 62N7, 91P9 and 92J7, mapped to the sex-chromosome multivalent in L. sinapis females (Fig. 5c), thus confirming that the BACFISH-identified bivalent in L. sinapis males is a pair of $\mathrm{Z}_{1}$ chromosomes that are orthologous to the $\mathrm{Z}_{1}$ chromosome in L. juvernica. In contrast, 8 of the $17 \mathrm{Z}_{1}$-derived $\mathrm{BAC}$ probes of $L$. juvernica mapped to one bivalent and 9 probes to another bivalent in $L$. reali males (Fig. 2e). This result showed that in $L$. reali, the $\mathrm{Z}_{1}$ of $L$. juvernica and $L$. sinapis split into two chromosomes in the region between the $a p$ and ket orthologs (BAC probes 53C10 and 91P9, respectively) (Fig. 2). The order of $17 \mathrm{BAC}$ loci in the respective bivalents was conserved in all three species. One of the BAC probes, 62N7, representing one of the two mapped bivalents and two BAC probes, 91P9 and 92J7, representing the other bivalent hybridised to the sex-chromosome multivalent in $L$. reali females (Fig. 5e). This result clearly showed that the mapped bivalents represent two of the four $\mathrm{Z}$ chromosomes in $L$. reali. We marked them as $Z_{1}$ and $\mathrm{Z}_{4}$ chromosomes (Fig. 2).

\section{BAC-FISH mapping of $Z_{2}$ and $Z_{3}$ chromosomes}

To determine the origin of the other two $\mathrm{Z}$ chromosomes in $L$. juvernica, we performed FISH mapping of BAC clones containing putative sex-linked Leptidea orthologs of B. mori autosomal genes that were identified by array-CGH (Fig. 1b). Sixteen BAC probes containing orthologs of B. mori chr. 7, chr. 11 and chr. 24 genes mapped to a single bivalent in $L$. juvernica males and covered the entire length of the bivalent (Fig. 3a). One representative BAC probe (94J6) of these 16 hybridised to one chromosome in the 
Fig. 2 BAC-FISH mapping of $\mathrm{Z}_{1}$ chromosome in Leptidea juvernica and $L$. sinapis and $\mathrm{Z}_{1}$ and $\mathrm{Z}_{\mathbf{4}}$ chromosomes in L. reali. Upper panel: male pachytene chromosomes showing hybridisation signals of Cy3- or fluorescein-labelled 14 BAC probes containing Leptidea orthologs of Bombyx mori Z-linked and $3 \mathrm{BAC}$ probes of chromosome 17linked genes. Chromosomes were stained with DAPI (grey). Bar $=10 \mu \mathrm{m}$. Asterisk indicates the beginning of region orthologous to B. mori chr. 17 . (a, b) L. juvernica. (c, d) $L$. sinapis. (e) L. reali. Lower panel: schematic illustrations of comparative gene mapping between three Leptidea species and $B$. mori. The underlined genes on $B$. mori chromosomes indicate orthologs that mapped to autosomes in Leptidea species (Supplementary Fig. S3a).
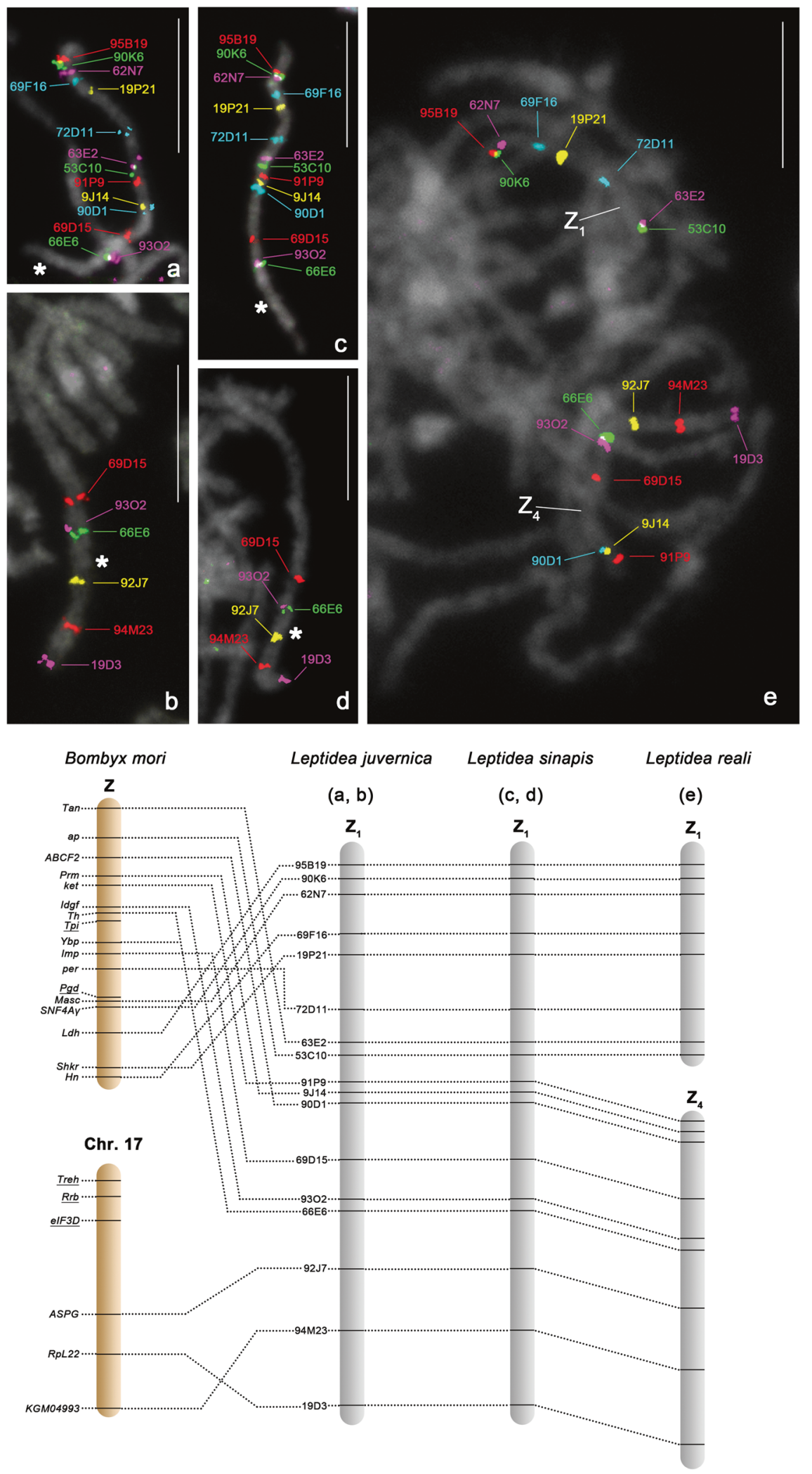

sex-chromosome multivalent in L. juvernica females (Fig. 5a). Thus, the male bivalent identified by BAC-FISH corresponds to another pair of four $\mathrm{Z}$ chromosomes in
L. juvernica, referred to as the $\mathrm{Z}_{2}$ chromosome. Another BAC-FISH experiment showed that three respective BAC probes containing autosomal orthologs of B. mori chr. 
Fig. 3 BAC-FISH mapping of $\mathrm{Z}_{2}$ chromosome in three Leptidea species. Upper panel: male pachytene chromosomes showing hybridisation signals of Cy3- or fluorescein-labelled 16 BAC probes containing Leptidea orthologs of Bombyx mori chr. 7, chr. 11 and chr. 24 genes. Chromosomes were stained with DAPI (grey). Bar $=10 \mu \mathrm{m}$. a $L$. juvernica. b $L$. sinapis. c L. reali. Lower panel: schematic illustrations of comparative gene mapping between three Leptidea species and $B$. mori. The underlined genes on $B$. mori chromosomes indicate orthologs that mapped to autosomes in Leptidea species (Supplementary Fig. S3b, c).
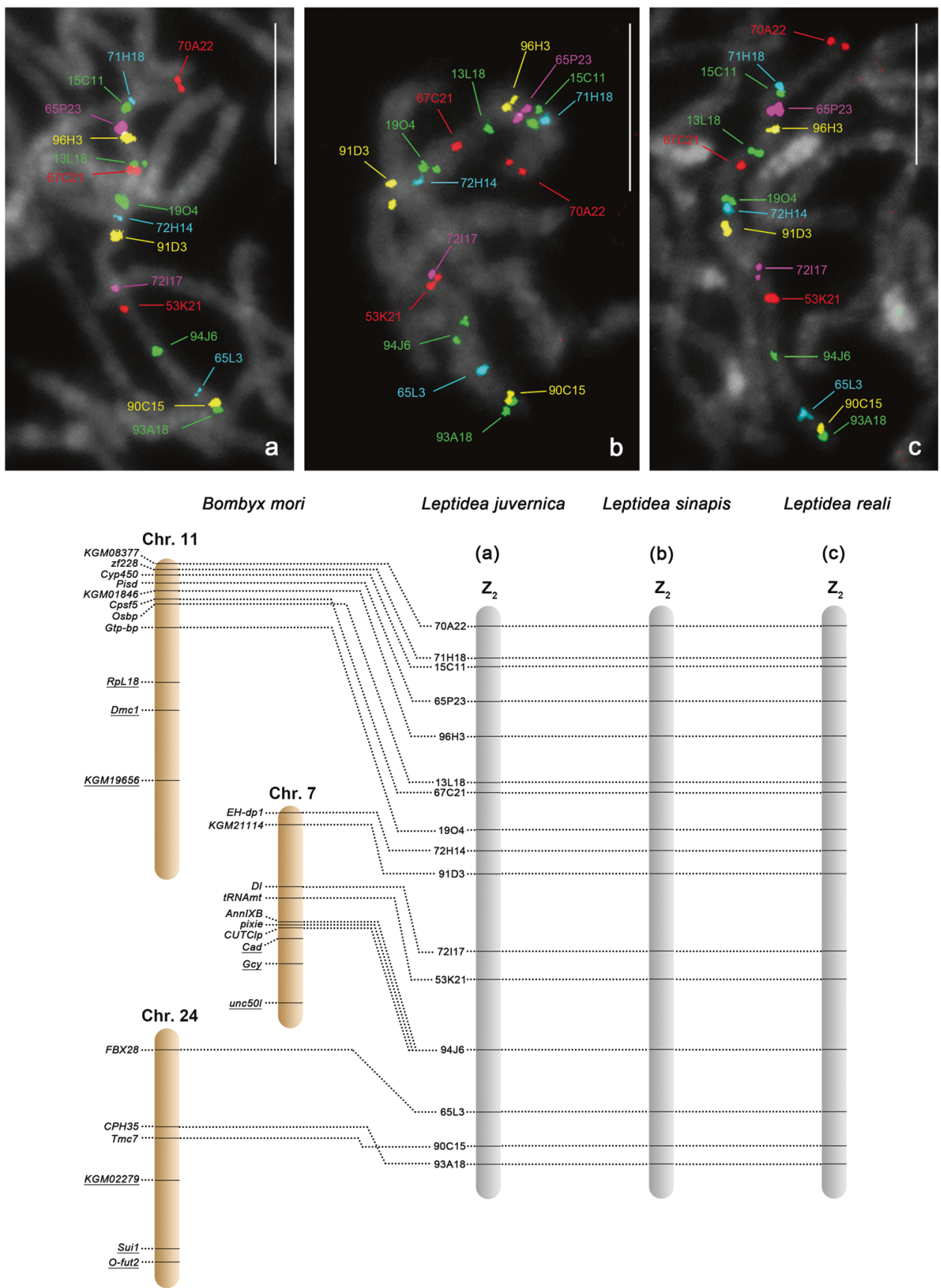

7, chr. 11 and chr. 24 genes indeed map to autosomes in L. juvernica males (see the underlined genes in Fig. 3 and Supplementary Fig. S3b, c). Based on the above results, we concluded that the $\mathrm{Z}_{2}$ chromosome of $L$. juvernica consists of three segments corresponding to parts of $B$. mori chr. 11, chr. 7 and chr. 24 (Fig. 3, lower panel).

All 16 BAC probes that mapped to the $\mathrm{Z}_{2}$ chromosome of $L$. juvernica also mapped to the respective bivalent in $L$. sinapis and $L$. reali males. In addition, the order of mapped probes was also fully conserved in all three species (Fig. 3b, c). The representative BAC 94J6 probe of these 16 also hybridised to one chromosome of the sex-chromosome multivalent in $L$. sinapis and $L$. reali females (Fig. 5 c, e), confirming that it is indeed a $\mathrm{Z}_{2}$ chromosome in both species.

Eight BAC probes containing orthologs of B. mori chr. 8 genes mapped to two bivalents in $L$. juvernica males (Fig. 4a). One of the BAC probes (62A6), representing one of the two bivalents and another BAC probe (69P11), representing the other bivalent hybridised to the sexchromosome multivalent in L. juvernica females (Fig. 5a), suggesting that both bivalents correspond to two of four 
Fig. 4 BAC-FISH mapping of $Z_{3}$ and $Z_{4}$ chromosomes in Leptidea juvernica and $\mathrm{Z}_{3}$ chromosome in $L$. sinapis and L. reali. Upper panel: male pachytene chromosomes showing hybridisation signals of Cy3- or fluorescein-labelled ten BAC probes containing Leptidea orthologs of Bombyx mori chr. 8 and chr. 15 genes.

Chromosomes were stained with DAPI (grey). Bar $=10 \mu \mathrm{m}$. a $L$. juvernica. b $L$. sinapis. $\mathbf{c} L$. reali. Lower panel: schematic illustrations of comparative gene mapping between three Leptidea species and $B$. mori. The underlined genes on $B$. mori chromosomes indicate orthologs that mapped to autosomes in Leptidea species

(Supplementary Fig. S3c).
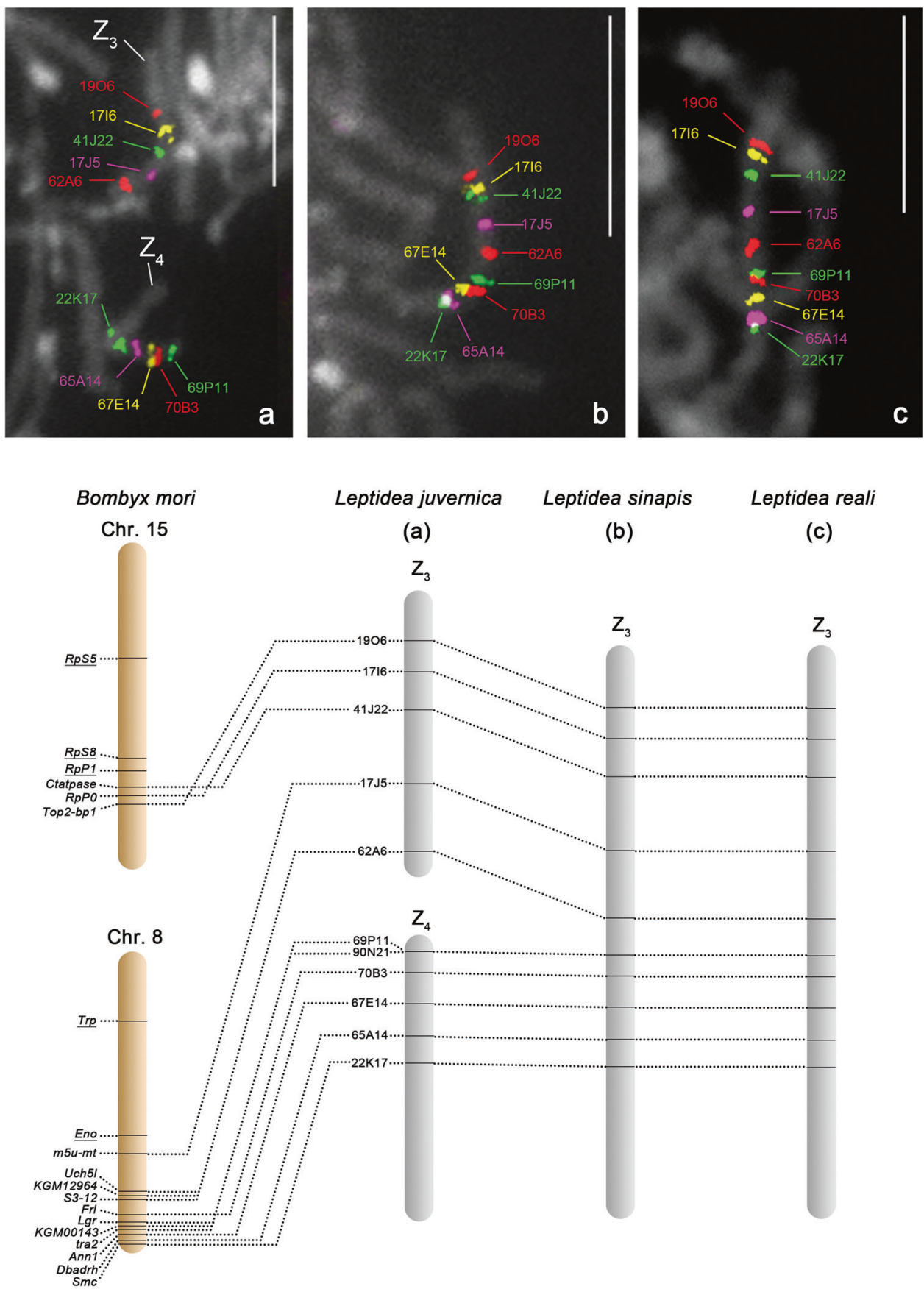

$\mathrm{Z}$ chromosomes in this species. We marked them as $Z_{3}$ and $\mathrm{Z}_{4}$ chromosomes (Fig. 4, lower panel). To get more markers on $Z_{3}$, we searched in the assembled genome sequence of L. sinapis (Talla et al. 2017) for a scaffold containing an ortholog of the m5u-mt gene located on B. mori chr. 8 (Fig. 4). We found that the scaffold_39 in the L. sinapis genome sequence consists not only of the $m 5 u$ - $m t$ gene ortholog but also of the ortholog of Ctatpase gene located on B. mori chr. 15 (Supplementary Table S2). This finding allowed us to select and test six BAC clones containing orthologs of B. mori chr. 15 genes (Supplementary Table
S1). Three BAC probes of these six, 41J22, $17 \mathrm{I} 6$ and 19O6, mapped to the $\mathrm{Z}_{3}$ bivalent in $L$. juvernica males (Fig. 4a). We also confirmed that two and three BAC probes containing putative autosomal orthologs of B. mori chr. 8 and chr. 15 genes, respectively, mapped to autosomes in L. juvernica males (see the underlined genes in Fig. 4 and Supplementary Fig. S3c). Taken together, we conclude that the $\mathrm{Z}_{3}$ chromosome of $L$. juvernica consists of two segments, one corresponding to a part of chr. 8 and one to a part of chr. 15 in B. mori, and $\mathrm{Z}_{4}$ contains the other part corresponding to B. mori chr. 8 . 


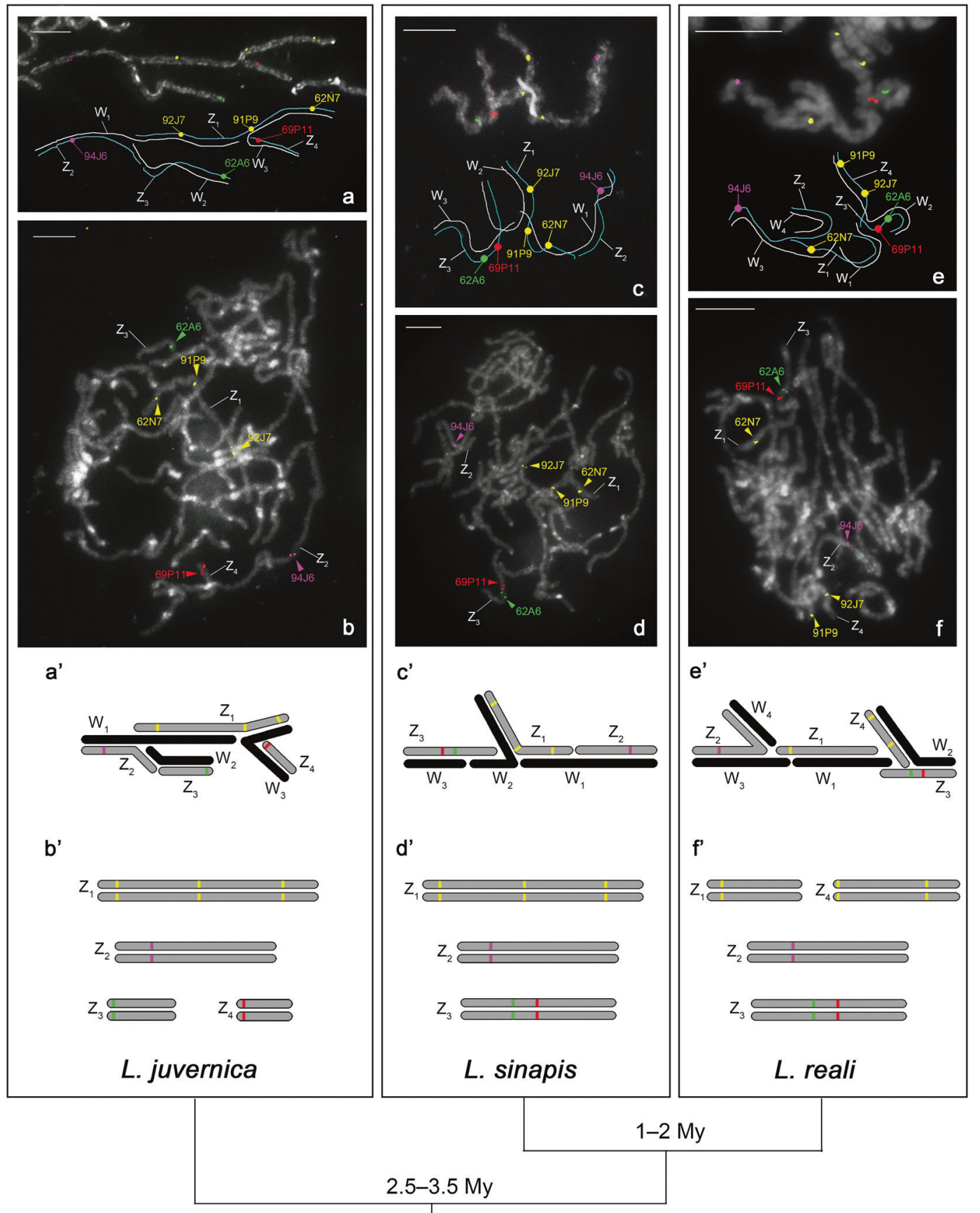

Fig. 5 BAC-FISH analyses of multiple sex-chromosomes in three Leptidea species. Upper panel (a-f): FISH mapping of BAC clones representing respective $\mathrm{Z}$ chromosomes in female and male pachytene chromosomes. BAC clones (see Supplementary Table S1) mapping to different $\mathrm{Z}$ chromosomes are marked with a different colour. Chromosomes were stained with DAPI (grey). Bar $=10 \mu \mathrm{m}$. (a BAC-FISH image and schematic drawing of the sex-chromosome multivalent in female pachytene of $L$. juvernica. b Male pachytene complement of L. juvernica. c BAC-FISH image and schematic drawing of the sexchromosome multivalent in female pachytene of L sinapis. d Male pachytene complement of $L$. sinapis. e BAC-FISH image and

All ten $\mathrm{BAC}$ probes that mapped to $\mathrm{Z}_{3}$ and $\mathrm{Z}_{4}$ chromosomes in $L$. juvernica mapped to each single bivalent in schematic drawing of the sex-chromosome multivalent in female pachytene of $L$. reali. f Male pachytene complement of $L$. reali. Lower panel (a'-f'): schematic illustrations of multiple sex-chromosomes in three Leptidea species based on BAC-FISH results shown in upper panel. a' $L$. juvernica female. b' L. juvernica male. c' $L$. sinapis female. d' $L$. sinapis male. e' $L$. reali female. f' $L$. reali male. $\mathrm{Z}$ and $\mathrm{W}$ chromosomes are coloured grey and black, respectively. The phylogenetic relationships and estimated divergence times (My, million years) between the species are shown below the lower panel (Šíchová et al. 2015; Talla et al. 2017, 2019a).

L. sinapis and $L$. reali males (Fig. $4 \mathrm{~b}, \mathrm{c}$ ). The fact that both $\mathrm{Z}_{3}$ and $\mathrm{Z}_{4}$ of $L$. juvernica contain orthologs of B. mori chr. 8 

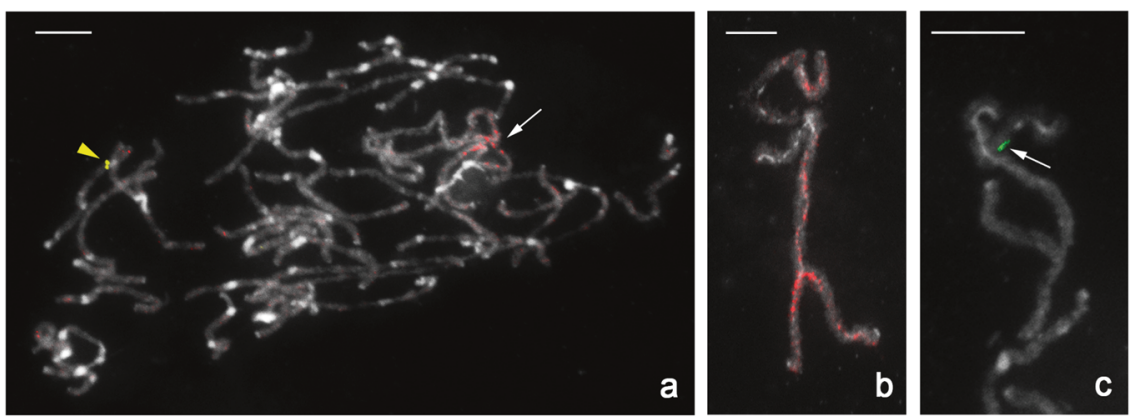

d

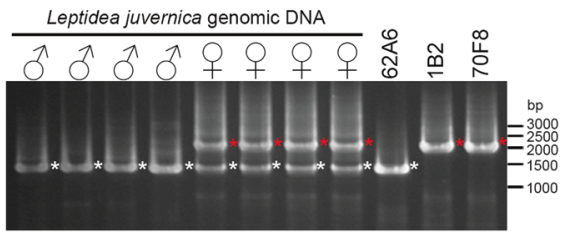

e

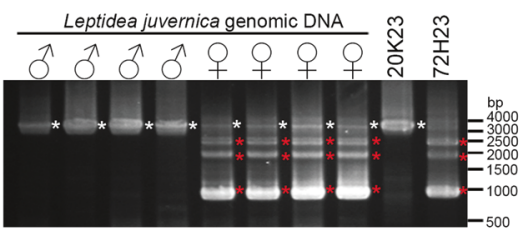

Fig. 6 Analysis of $\mathbf{W}$ chromosomes in Leptidea species. a-c FISH with BAC probes derived from $\mathrm{W}$ chromosomes. Red, green and yellow represent hybridisation signals of BAC probes $1 \mathrm{~B} 2,1 \mathrm{~J} 4$ and 1A2, respectively. Chromosomes were stained with DAPI (grey). Bar $=10 \mu \mathrm{m}$. a Cy3-labelled 1B2 probe (red) painted part of the sexchromosome multivalent (arrow) in female pachytene complement of L. juvernica and fluorescein-labelled $1 \mathrm{~A} 2$ probe (yellow arrowhead) hybridised to an autosome bivalent. Sex-chromosome multivalents of L. juvernica showing painted segments by $1 \mathrm{~B} 2$ probe (red) in three $\mathrm{W}$ chromosomes (b) and hybridisation signals of the $1 \mathrm{~J} 4$ probe (green and arrow in c). d Gel showing PCR results using a primer set (Supplementary Table S1) designed based on the partial exon

indicates that they arose by fission (see 'Discussion'). The order of ten BAC loci remained unchanged in L. sinapis and L. reali (Fig. $4 \mathrm{~b}, \mathrm{c}$ ). We also confirmed that two representative BAC probes of these ten, $62 \mathrm{~A} 6$ and 69P11, hybridised to one chromosome of the sex-chromosome multivalent in $L$. sinapis and $L$. reali females (Fig. 5c, e). This chromosome was designated as $\mathrm{Z}_{3}$ in L. sinapis and L. reali.

To confirm that the $\mathrm{Z}$ chromosomes shown in Figs. 2-4 are indeed different individual chromosomes, we performed BAC-FISH mapping of six representative probes in males of each Leptidea species. These six BAC probes mapped to four chromosomes $\left(\mathrm{Z}_{1}-\mathrm{Z}_{4}\right)$ in L. juvernica (Fig. 5b), three chromosomes $\left(\mathrm{Z}_{1}-\mathrm{Z}_{3}\right)$ in L. sinapis (Fig. 5d) and four chromosomes $\left(\mathrm{Z}_{1}-\mathrm{Z}_{4}\right)$ in $L$. reali (Fig. $\left.5 \mathrm{f}\right)$, respectively. Thus, we successfully identified all $\mathrm{Z}$ chromosomes in all three Leptidea species.

\section{Analysis of molecular differentiation in W chromosomes}

BAC clones derived from $\mathrm{W}$ chromosomes of $L$. juvernica were identified by FISH-based screening (Supplementary Text 2 and Supplementary Figs S1, S4). The W-BAC 1B2 probe painted part of the sex-chromosome multivalent in sequences of the Leptidea ortholog of the B. mori Uch5l gene. Genomic DNAs of both sexes and DNAs of BAC clones 62A6, 1B2 and 70F8 were used as templates. White and red asterisks indicate an amplified sequence of the Uch5l ortholog and a female-specific (Wlinked) sequence of this ortholog, respectively. e Gel showing PCR results using a primer set (Supplementary Table S1) designed based on the partial exon sequences of the Leptidea ortholog of the B. mori Gst8 gene. Genomic DNAs of both sexes and DNAs of BAC clones $20 \mathrm{~K} 23$ and $72 \mathrm{H} 23$ were used as templates. White asterisks indicate an amplified sequence of the Gst 8 ortholog and red asterisks a femalespecific (W-linked) sequence of this ortholog.

L. juvernica females (Fig. 6a, b) and another W-BAC clone $1 \mathrm{~J} 4$ hybridised to a specific region of the sex-chromosome multivalent in L. juvernica females (Fig. 6c). The 1B2 probe also painted part of the sex-chromosome multivalent in other two Leptidea species, whereas hybridisation signals of the $1 \mathrm{~J} 4$ probe were not detected in either of these species (Supplementary Fig. S5). Sequence analysis of sub-cloned $\mathrm{W}-\mathrm{BAC}$ clones $1 \mathrm{~B} 2$ and $1 \mathrm{~J} 4$ and blast searches showed that most of the sub-cloned sequences were part of transposable elements, but two sub-clones (Nos 11 and 18) were part of the Leptidea ortholog of the B. mori Uch5l gene (Supplementary Table S3 and Supplementary Fig. S6a), which mapped to the $\mathrm{Z}_{3}$ chromosome in L. juvernica (Fig. 4). This result suggests that the two sub-cloned sequences are part of a Whomologue of the $\mathrm{Z}_{3}$-linked ortholog of the $U$ ch $5 l$ gene.

We searched for W-specific sequences of the Uch $5 l$ ortholog by PCR with a set of designed primers (Supplementary Fig. S6a and Supplementary Table S1). PCR amplified two distinct fragments (1400 and $2095 \mathrm{bp}$ ) from female gDNA of $L$. juvernica, whereas only a single fragment was amplified from male gDNA (Fig. 6d). These PCR results also showed that the BAC clone 62A6, which mapped to the $\mathrm{Z}_{3}$ chromosome (Fig. 4), contains a common fragment of both sexes (Fig. 6d, white asterisks) and that the W-BAC clones $1 \mathrm{~B} 2$ and $70 \mathrm{~F} 8$, the latter identified by 
a

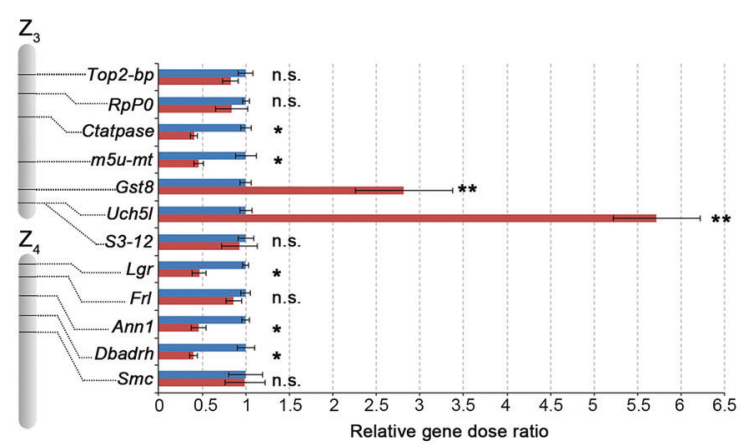

C

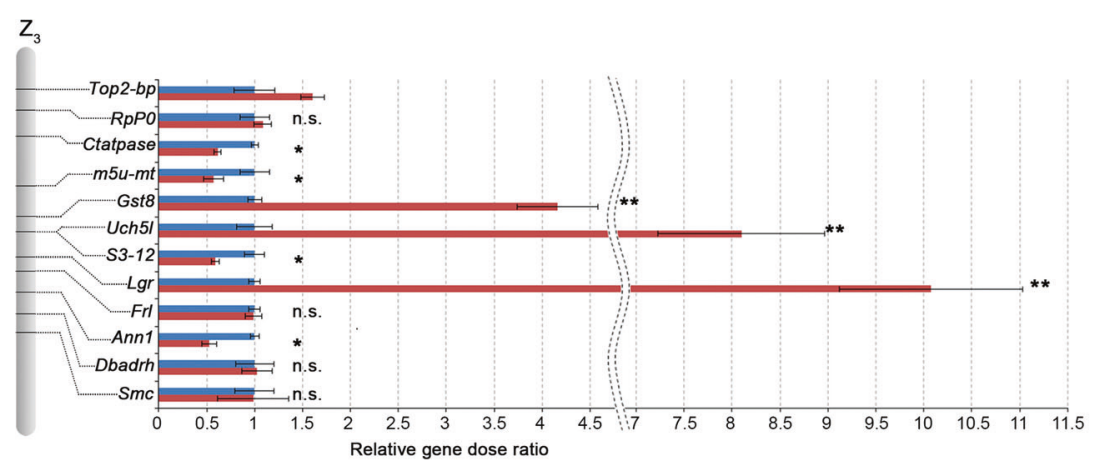

Fig. 7 Female-to-male gene dose ratios of Z-linked genes in three Leptidea species. Results of qPCR showing female (red columns) to male (blue columns) relative dose ratios of $\mathrm{Z}_{3^{-}}$and $\mathrm{Z}_{4}$-linked genes in L. juvernica (a) and $\mathrm{Z}_{3}$-linked genes in $L$. sinapis $(\mathbf{b})$ and $L$. reali $(\mathbf{c})$ normalised to the autosomal reference gene $R p S 5$ (average of target to reference gene dose in male $=1$ ). Error bars represent SDs calculated b

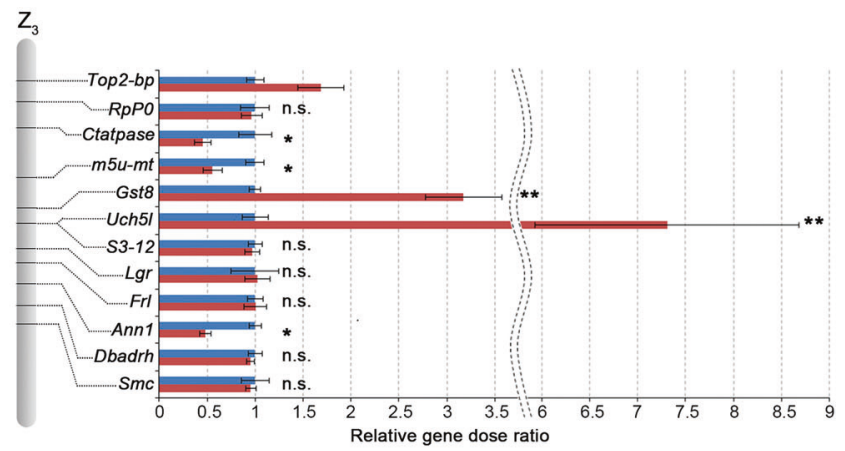

from three independent samples (Supplementary Tables S6, S7 and S8). Double asterisks, asterisks and n.s. indicate a significant multiple difference (female-to-male $>2: 1$ ), a significant twofold difference (female-to-male $=1: 2$ ), and no significant difference (female-to-male $=1: 1)$ in unpaired two-tailed $t$ test for unequal variances, respectively (Supplementary Tables S6, S7 and S8). further BAC library screening, contain a female-specific fragment (Fig. 6d, red asterisks). The female-specific fragment (Lj_Uch5l_W) and the common fragment ( $L j \_U c h 5 l \_Z$ ) share sequences in their exons, but differ quite considerably in their introns (Supplementary Fig. S6b and Supplementary Table S4). The differences between introns are mainly due to randomly occurring insertions in the $L j \_U c h 5 l \_W$ intron (Supplementary Figs S6c, S7). The female-specific fragment was also amplified from gDNAs of $L$. sinapis and $L$. reali females and most of their sequences were well conserved in all three species, except for several insertions or deletions (Supplementary Fig. S8). We designed a primer set based on female-specific sequence in the intron of the $U c h 5 l$ ortholog (Supplementary Table S5 and Supplementary Fig. S6b) to confirm the femalespecific insertion. PCR with the female-specific primer set amplified a 341-bp fragment from female gDNAs of all three species (Supplementary Fig. S6c, asterisks), whereas no 341-bp fragments were detected in male gDNAs.

We found a sex-specific polymorphism in the Leptidea ortholog of the Gst 8 gene, located near the $U c h 5 l$ gene on B. mori chr. 8 and we showed that the ortholog has a
W-linked copy. PCR with a set of designed primers (Supplementary Fig. S9a and Supplementary Table S1) amplified a single fragment from male gDNA of L. juvernica (Fig. 6e, white asterisks), whereas several distinct fragments were amplified from female gDNA (Fig. 6e, red asterisks). We identified clone $20 \mathrm{~K} 23$ containing a fragment of the Gst8 ortholog that was common to both sexes (Fig. 6e). The $20 \mathrm{~K} 23$ probe mapped to the same region of the $\mathrm{Z}_{3}$ chromosome in L. juvernica as the $62 \mathrm{~A} 6$ probe containing the Uch5l ortholog (Supplementary Fig. S9b). These results suggest that the fragment amplified from both sexes is derived from the $\mathrm{Z}_{3}$ chromosome. In contrast, the BAC clone $72 \mathrm{H} 23$ contained several distinct female-specific fragments of the Gst8 ortholog (Fig. 6e, red asterisks) and the $72 \mathrm{H} 23$ probe painted most of the $\mathrm{W}$ chromosomes in L. juvernica females (Supplementary Fig. S9c). Sequence analysis of the common fragment and the female-specific fragment of the Gst 8 ortholog revealed several femalespecific (W-specific) deletions in the introns and the occurrence of at least three distinct copies of the Gst8 ortholog on the L. juvernica W chromosomes (Supplementary Text 3 and Supplementary Fig. S9d). 
To estimate the copy number of Leptidea orthologs of the $U$ ch $5 l$ and Gst8 genes on the W chromosome(s) and to assess if other $\mathrm{Z}_{3^{-}}$and $\mathrm{Z}_{4}$-linked orthologs still remain covered on the $\mathrm{W}$ chromosome(s), we compared the relative gene dose of these orthologs between female and male gDNAs in the Leptidea species studied by qPCR (Fig. 7; Supplementary Fig. S10 and Supplementary Tables S6-S8). Because $\mathrm{Z}_{1}$ - and $\mathrm{Z}_{2}$-linked orthologs have been identified as sex-linked genes by array-CGH in L. juvernica (Figs. 1-3), female-to-male relative gene dose ratios of these orthologs should be 1:2. Accordingly, we confirmed a twofold difference between the female and male gene dose in all tested $\mathrm{Z}_{2}$-linked orthologs by qPCR in all three species (Supplementary Fig. S10). Results of qPCR with $\mathrm{Z}_{3^{-}}$and $\mathrm{Z}_{4}$-linked orthologs showed that the female-to-male relative gene dose ratios of the $U c h 5 l$ and $G s t 8$ orthologs are $~ 5.7: 1$ and 2.8:1 in L. juvernica (Fig. 7a), 7.3:1 and 3.1:1 in L. sinapis (Fig. 7b) and 8:1 and 4.1:1 in L. reali (Fig. 7c), respectively. Female-to-male relative gene dose ratios of orthologs of the Ctatpase, m5u-mt and Annl genes in all three species, Lgr and Dbadrh genes in L. juvernica, and the S3-12 gene in L. reali were 1:2 (Fig. 7 asterisks and Supplementary Tables S6-S8). In contrast, we found no significant difference between the female and male gene doses in orthologs of the $\mathrm{RpPO}, \mathrm{Frl}$ and Smc genes in all three species, Top2-bp and S3-12 genes in L. juvernica, S3-12, Lgr and Dbadrh genes in L. sinapis, and the Dbadrh gene in L. reali (Fig. 7 n.s. and Supplementary Tables S6-S8), suggesting that their orthologs also remained intact on the $\mathrm{W}$ chromosomes. Female-to-male relative gene dose ratios of the Top2-bp gene ortholog were $1: 1$ in $L$. juvernica but $\sim 1.6: 1$ in $L$. sinapis and $L$. reali. Results of $\mathrm{qPCR}$ showed a tenfold difference between the female and male gene dose of the Lgr ortholog in L. reali (Fig. 7c).

\section{Discussion}

In this work, we have deciphered the evolutionary origin of complex multiple sex-chromosomes in three cryptic Leptidea species. BAC-FISH mapping of Z-linked genes clearly showed that the multiple sex-chromosomes arose by several translocations and fusions between the ancestral WZ pair and autosomes, followed by several fissions (Figs. 2-4). The resulting 3-4 $\mathrm{Z}$ chromosomes are composed each of 2-3 conserved synteny blocks, in which the gene order remained well conserved in all three species. However, the $\mathrm{Z}$ chromosomes in individual species were differentiated by further rearrangements, either by fusion or fission (Fig. 5). In accordance with phylogenetic relationships between the three species (Dincă et al. 2011; Lukhtanov et al. 2011; Š́chová et al. 2015; Fig. 5 in this study), the $Z_{1}$ of L. juvernica and L. sinapis most likely split into two
$\mathrm{Z}$ chromosomes $\left(\mathrm{Z}_{1}\right.$ and $\left.\mathrm{Z}_{4}\right)$ in $L$. reali after $L$. reali and L. sinapis diverged from their common ancestor because both $\mathrm{Z}_{1}$ and $\mathrm{Z}_{4}$ of $L$. reali contain genes of the original Z-chromosome in the ancestral lepidopteran karyotype (Van't Hof et al. 2013; Ahola et al. 2014). The $Z_{3}$ of L. sinapis and $L$. reali corresponds to $\mathrm{Z}_{3}$ and $\mathrm{Z}_{4}$ chromosomes in L. juvernica (Fig. 4). Since both $\mathrm{Z}_{3}$ and $\mathrm{Z}_{4}$ of L. juvernica contain orthologs of $B$. mori chr. 8 genes that are located on one autosome in the ancestral lepidopteran karyotype, the two $\mathrm{Z}$ chromosomes most likely originated by fission of $\mathrm{Z}_{3}$ chromosome after $L$. juvernica diverged from $L$. sinapis plus $L$. reali. These findings strongly suggest that the sex-chromosome constitution in the common ancestor of these three Leptidea species was similar to that of L. sinapis (Fig. 5).

Conserved synteny blocks and conserved order of genes in the multiple $\mathrm{Z}$ chromosomes of Leptidea species studied are in line with current knowledge of the genome architecture in Lepidoptera. Most lepidopteran species have a chromosome number equal to or near the ancestral number of $n=31$, and synteny of genes, including their order, is relatively well conserved even among distant species (Van't Hof et al. 2013; Ahola et al. 2014; Yasukochi et al. 2016). The model species for Lepidoptera, B. mori, has a haploid chromosome number of $n=28$ and its karyotype evolved by three chromosome fusions from the ancestral $n=31$, except for a few inversions and translocations (Van't Hof et al. 2013; Ahola et al. 2014; Yasukochi et al. 2016). A similar explanation applies to the karyotype evolution in other lepidopteran species with reduced chromosome numbers (Pringle et al. 2007; Yasukochi et al. 2009; Yoshido et al. 2011b). Our results, together with earlier reported variation in chromosome numbers in the genus Leptidea (Dincă et al. 2011; Lukhtanov et al. 2011; Šíchová et al. 2015, 2016), suggest dynamic genome rearrangements that occurred not only in sex chromosomes but also in autosomes during karyotype evolution before Leptidea species diverged from a common ancestor. Consequently, the Leptidea species do not exhibit a conserved macrosynteny of genes compared with the putative ancestral karyotype of Lepidoptera (Van't Hof et al. 2013; Ahola et al. 2014). The recent genome assembly of another pierid butterfly, Pieris napi, showed conserved microsynteny blocks of genes in autosomes but broken macrosynteny blocks, also suggesting dynamic genome rearrangements (Hill et al. 2019).

Based on the above findings and our results, we proposed a hypothetical scenario of the evolution of multiple sexchromosomes in the three Leptidea species studied (Fig. 8). Given the similar constitution of sex chromosomes, we infer that major genome reshuffling occurred in the common ancestor of these Leptidea species. As a result, proto-WZ chromosomes in ancestral females originated by 


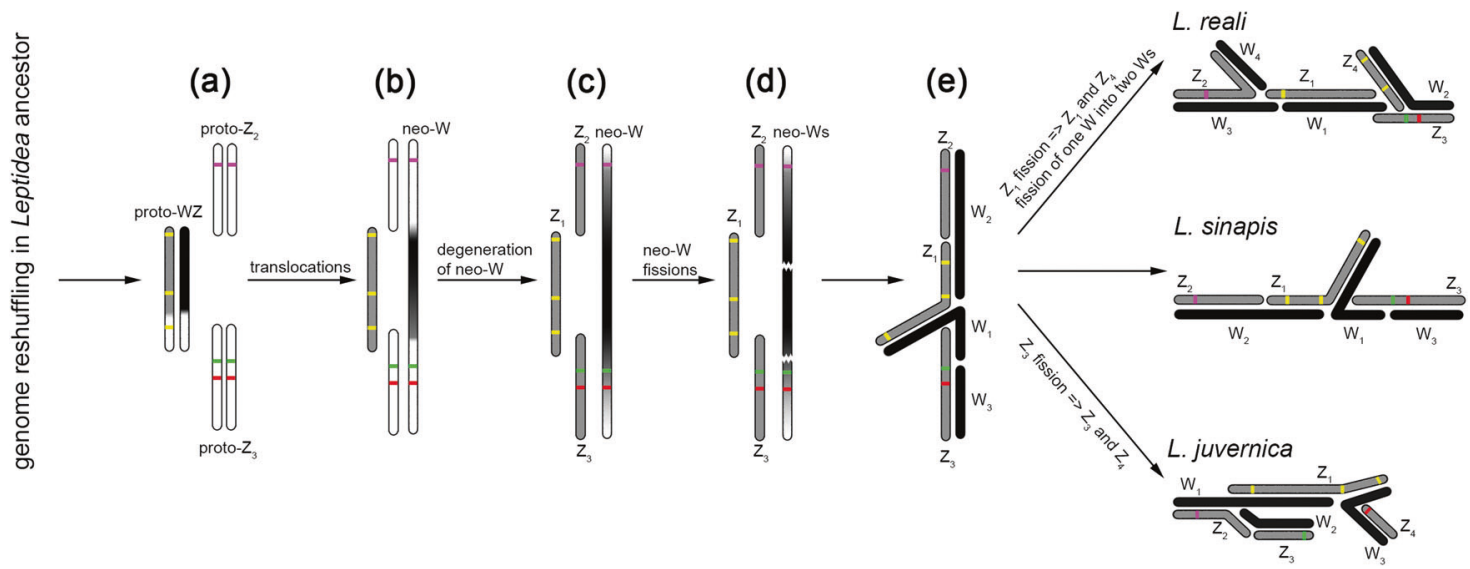

Fig. 8 Hypothetical scenario of the multiple sex-chromosome evolution in three Leptidea species. This scenario is based on the results of BAC-FISH mapping presented in this study. The proposed steps in the evolution of multiple sex-chromosomes are shown in a-e. Proto-WZ indicates a putative pair of ancestral sex-chromosomes (W

translocation of a part of the autosome orthologous to B. mori chr. 17 (Fig. 8a, white parts of proto-WZ) onto the ancestral pair of WZ sex-chromosomes and two pairs of autosomes, referred to as proto- $Z_{2}$ and proto- $Z_{3}$, arose by fusion of several synteny blocks of the ancestral lepidopteran karyotype (Fig. 8a). At that time, ancestral males already had the current structure of $Z_{1}, Z_{2}$ and $Z_{3}$ chromosomes as shown in Fig. $5 \mathrm{~d}, \mathrm{~d}^{\prime}$ for $L$. sinapis, but proto- $\mathrm{Z}_{2}$ and proto- $Z_{3}$ were still autosomes in both sexes. In the next step, proto- $Z_{2}$ and proto- $Z_{3}$ were translocated onto the proto-W chromosome and their unfused homologues thus turned from autosomes to $\mathrm{Z}_{2}$ and $\mathrm{Z}_{3}$ sex-chromosomes (Fig. $8 b)$. In the resulting neo-W chromosome, the originally autosomal parts gradually degraded due to the absence of recombination in female meiosis (Fig. 8c). According to the degeneration of genes on the neo-W chromosomes demonstrated by the qPCR results (Fig. 7 and Supplementary Fig. S10), the proto- $Z_{2}$ translocation onto the proto-W chromosome is most probably older than the proto- $Z_{3}$ translocation. In the final step, two fissions occurred in the neo-W (Fig. 8d), resulting in a multiple sex-chromosome constitution with three $\mathrm{W}\left(\mathrm{W}_{1-3}\right)$ and three $\mathrm{Z}\left(\mathrm{Z}_{1-3}\right)$ chromosomes, as found in L. sinapis females (Fig. 8e). Subsequently, during the process of speciation, several further rearrangements of sex chromosomes contributed to the differentiation of closely related species. Fission of one of the $\mathrm{W}$ chromosomes and fission of the $\mathrm{Z}_{1}$ chromosome led to the $\mathrm{W}_{1-4} \mathrm{Z}_{1-4}$ constitution, as found in $L$. reali, whereas the $\mathrm{Z}_{3}$ fission resulted in the $\mathrm{W}_{1-3} \mathrm{Z}_{1-4}$ constitution, as found in L. juvernica (Fig. 8e). In this work, we showed that most homologues of $\mathrm{Z}_{2}$-linked genes decayed in the $\mathrm{W}$ chromosomes of all three species (Supplementary Fig. S10), while some homologues of $\mathrm{Z}_{3}$ - and $\mathrm{Z}_{4}$-linked genes are still preserved (Fig. 7). However, it can be expected that and $\mathrm{Z}$ ), proto- $\mathrm{Z}_{2}$ and proto- $\mathrm{Z}_{3}$ two ancestral autosomes of the common ancestor of three Leptidea species. Positions of representative BAC clones for the respective $\mathrm{Z}$ chromosomes are indicated in yellow, purple, red and green as in Fig. 5.

degeneration of the originally autosomal parts of the $\mathrm{W}$ chromosomes, corresponding to $\mathrm{Z}_{3}$ and $\mathrm{Z}_{4}$ chromosomes, will proceed through the accumulation of transposable elements, duplications, insertions and/or deletions (Fig. 6d-e; Supplementary Figs S6-S9 and Supplementary Table S3). Especially qPCR results strongly suggest that two $U c h 5 l$ and Gst 8 orthologs in all three species, and thus in their common ancestor, and $L g r$ ortholog in $L$. reali were amplified on the $\mathrm{W}$ chromosome(s) during the $\mathrm{W}$ chromosome degeneration (Fig. 7, double asterisks; cf. Bachtrog et al. 2019). Nevertheless, the finding of wellpreserved homologues of genes of autosomal origin in the W chromosomes supports the proposed hypothetical scenario of evolution of multiple sex-chromosomes in Leptidea species.

In Lepidoptera, the correspondence of 'ancestral' Zlinked genes is highly conserved across the phylogenetic tree (Beldade et al. 2009; Yasukochi et al. 2009; Nguyen et al. 2013; Van't Hof et al. 2013; Dalíková et al. 2017a; Fraïsse et al. 2017), but the gene order may be changed by intrachromosomal rearrangements (Yasukochi et al. 2009; Van't Hof et al. 2013). A similar picture emerged in this study for Leptidea species. Despite many chromosomal rearrangements in their genomes, most 'ancestral' Z-linked genes mapped to the $\mathrm{Z}_{1}$ (and $\mathrm{Z}_{4}$ in $L$. reali) chromosome, except for a few genes (maximum 9\%; see array-CGH results in Fig. 1b), but the gene order of ancestral Z-linked genes was changed compared with the $\mathrm{Z}$ chromosome of B. mori (Fig. 2). Lepidopteran $\mathrm{Z}$ chromosomes are known to play an important role in sex determination (Kiuchi et al. 2014), adaptation and speciation (Presgraves 2002; Dopman et al. 2005). The fact that the synteny block of the 'ancestral' Z-linked genes escaped the dynamic reorganisation of Leptidea genomes and remained conserved is 
consistent with the key role of $\mathrm{Z}$ chromosomes in the evolution of Lepidoptera.

In most lepidopteran species, the maternally inherited W chromosome is composed of heterochromatin and, due to the absence of recombination, is characterised by extensive genetic erosion and accumulation of repetitive DNA sequences (Abe et al. 2005; Fuková et al. 2007; Marec et al. 2010; Yoshido et al. 2016; Dalíková et al. 2017b). Evolutionary mechanisms of this genetic erosion have been demonstrated in the $\mathrm{Y}$ chromosomes of species with male heterogamety, especially in the Drosophila genus (Bachtrog 2005, 2013; Charlesworth et al. 2005). In evolutionary old and well-differentiated $\mathrm{W}$ chromosomes, homologous sequences of the 'ancestral' Z-linked genes were rarely found (Gotter et al. 1999; Van't Hof et al. 2013). The multiple $\mathrm{W}$ chromosomes in three Leptidea species represent in fact evolutionary strata (Wright et al. 2016) of different ages and levels of differentiation that contain each a segment of autosomal origin (Fig. 8). Taking into account the estimated divergence times, which range from 1-2 million years in $L$. sinapis vs. $L$. reali to 2.5-3.5 million years in $L$. juvernica vs. the two other species (Talla et al. 2017, 2019a), these W chromosomes can be considered evolutionarily young and allow us to compare the level of their differentiation. We identified $\mathrm{W}$ homologues of $\mathrm{Z}_{3^{-}}$and $\mathrm{Z}_{4}$-linked genes in all three species with some evidence of ongoing molecular differentiation, such as insertions, deletions and duplications (Fig. 6 and Supplementary Figs S6-S9). Moreover, about half of the examined $\mathrm{Z}_{3^{-}}$and $\mathrm{Z}_{4}$-linked genes still had their homologues on the neo-W chromosomes in all three species (Fig. 7). The level of differentiation of these neo-W chromosomes thus roughly corresponds to the differentiation of the 1 million years old Drosophila miranda neo-Y chromosome, in which more than $40 \%$ of the genes initially present on the ancestral neo-Y chromosome became pseudogenes or was completely lost (Bachtrog 2013). However, we found no evidence of $\mathrm{W}$ homologues of $\mathrm{Z}_{1^{-}}$and $\mathrm{Z}_{2}$-linked genes, suggesting advanced molecular differentiation of the relevant $\mathrm{W}$ chromosomes (Supplementary Fig. S10) comparable to the neo-W chromosome of Danaus species, which is believed to be older than 5 million years (Mongue et al. 2017). A relatively young neo-W chromosome with incomplete degeneration of the originally autosomal segment was also described in a wild silkmoth, S. cynthia walkeri (Yoshido et al. 2016). On the contrary, in evolutionary old neo-sex chromosomes that arose by fusion of ancestral sex-chromosomes with an autosome, it is difficult to demonstrate the neo- $\mathrm{W}$ chromosome due to progressive degeneration and the absence of homology (Mongue et al. 2017; Picq et al. 2018; Carabajal Paladino et al. 2019).
We reconstructed the evolution of multiple sexchromosomes in three cryptic Leptidea species and identified species-specific differences in their composition. Could differences in sex-chromosome constitutions between these species have contributed to their speciation? Our results suggest that multiple sex-chromosome systems predated the formation of Leptidea species studied. Thus, the initial sexchromosome turnover could not have played a role in reproductive isolation between these species. However, subsequent structural rearrangements leading to a speciesspecific number of multiple sex-chromosomes, namely fissions of several neo-sex chromosomes, could have significantly contributed to reproductive isolation due to missegregation of these neo-sex chromosomes in hybrids. In addition, different rates of neo-W chromosome degeneration (Fig. 7) could have also contributed to the divergence of Leptidea populations (Filatov 2018). A recent analysis of the whole-genome sequence data did not find any traces of post-divergence gene flow between these species (Talla et al. 2019a). These results suggest well-established reproductive barriers between these species, which include strong pre-mating reproductive isolation because females only accept conspecific males (Friberg et al. 2008; Dincă et al. 2013). The three Leptidea species showed a considerably lower level of genome-wide diversity than most other butterflies examined, indicating reduced effective population sizes (Talla et al. 2019b). They also showed a significantly reduced genetic diversity on the 'ancestral' Z-linked genes (corresponding to $\mathrm{Z}_{1}$ in this study, multiple $\mathrm{Z}$-chromosomes were not considered) and a significantly higher level of genetic differentiation on the 'ancestral' Z-linked genes in comparison with the 'ancestral' autosomal genes (Talla et al. 2019a). Especially the latter results are consistent with the so-called 'Faster-Z effect', which means that the sexlinked genes are subjected to a faster rate of evolution (Mank et al. 2010). In Leptidea species, we showed that different sets of originally autosomal genes have become Z-linked. This greatly increased the number of Z-linked genes, which could significantly accelerate the accumulation of genetic incompatibilities between populations, thus contributing to their divergence and subsequent speciation (cf. Turelli and Begun 1997).

\section{Data availability}

The raw reads generated in this study have been deposited in the NCBI Sequence Read Archive (SRA) database under the accession number SRR10381488 (Bioproject PRJNA586890). Other datasets generated in this study are available in the Dryad repository (https://doi.org/10.5061/ dryad.h70rxwddw). The custom Python script used for analysis of array-CGH data is available at https://github. com/avolenikova/aCGH_scripts. 
Acknowledgements We are very grateful to Jaroslav Doležel for his great support of this research and for enabling the use of facilities at the Centre of Plant Structural and Functional Genomics, Institute of Experimental Botany CAS, Olomouc, Czech Republic. Our thanks go to Marie Korchová for excellent technical assistance and Radomíra Tušková for the preparation of microplates with BAC clones of the Leptidea juvernica library. We also wish to thank Magda Zrzavá, Zdeněk Hanč and Zdeněk Faltýnek Fric for their help in collecting adult specimens of $L$. juvernica and $L$. sinapis. Last but not least, we are grateful to the editor and three anonymous reviewers for their valuable comments on this manuscript. Access to computing and storage facilities owned by parties and projects contributing to the National Grid Infrastructure MetaCentrum provided under the programme 'Projects of Large Research, Development, and Innovations Infrastructures' (CESNET LM2015042), is greatly appreciated. This research was funded by grant $14-22765$ S and follow-up grant 1713713 S of the Czech Science Foundation (CSF). Publishing was supported by CSF grant 20-13784S given to FM. PN was supported by CSF grants 17-17211S and 20-20650Y. RV acknowledges support from project CGL2016-76322-P (AEI/FEDER, UE).

\section{Compliance with ethical standards}

Conflict of interest The authors declare that they have no conflict of interest.

Publisher's note Springer Nature remains neutral with regard to jurisdictional claims in published maps and institutional affiliations.

Open Access This article is licensed under a Creative Commons Attribution 4.0 International License, which permits use, sharing, adaptation, distribution and reproduction in any medium or format, as long as you give appropriate credit to the original author(s) and the source, provide a link to the Creative Commons license, and indicate if changes were made. The images or other third party material in this article are included in the article's Creative Commons license, unless indicated otherwise in a credit line to the material. If material is not included in the article's Creative Commons license and your intended use is not permitted by statutory regulation or exceeds the permitted use, you will need to obtain permission directly from the copyright holder. To view a copy of this license, visit http://creativecommons. org/licenses/by/4.0/.

\section{References}

Abe H, Mita K, Yasukochi Y, Oshiki T, Shimada T (2005) Retrotransposable elements on the $\mathrm{W}$ chromosome of the silkworm, Bombyx mori. Cytogenet Genome Res 110:144-151

Ahola V, Lehtonen R, Somervuo P, Salmela L, Koskinen P, Rastas P et al. (2014) The Glanville fritillary genome retains an ancient karyotype and reveals selective chromosomal fusions in Lepidoptera. Nat Commun 5:4737

Andrews S (2010) FastQC: a quality control tool for high throughput sequence data. http://www.bioinformatics.babraham.ac.uk/projects/ fastqc

Bachtrog D (2005) Sex chromosome evolution: molecular aspects of Y chromosome degeneration in Drosophila. Genome Res 15:1393-1401

Bachtrog D (2013) Y-chromosome evolution: emerging insights into processes of Y-chromosome degeneration. Nat Rev Genet 14:113-124

Bachtrog D, Mahajan S, Bracewell R (2019) Massive gene amplification on a recently formed Drosophila Y chromosome. Nat Ecol Evol 3:1587-1597
Bachtrog D, Mank JE, Peichel CL, Kirkpatrick M, Otto SP, Ashman T et al. (2014) Sex determination: why so many ways of doing it? PLoS Biol 12:e1001899

Baker RH, Wilkinson GS (2010) Comparative genomic hybridization (CGH) reveals a neo-X chromosome and biased gene movement in stalk-eyed flies (genus Teleopsis). PLoS Genet 6:e1001121

Beldade P, Saenko SV, Pul N, Long AD (2009) A gene-based linkage map for Bicyclus anynana butterflies allows for a comprehensive analysis of synteny with the lepidopteran reference genome. PLoS Genet 5:e1000366

Bolger AM, Lohse M, Usadel B (2014) Trimmomatic: a flexible trimmer for Illumina sequence data. Bioinformatics 30: 2114-2120

Campbell P, Good JM, Dean MD, Tucker PK, Nachman MW (2012) The contribution of the $\mathrm{Y}$ chromosome to hybrid male sterility in house mice. Genetics 191:1271-1281

Carabajal Paladino LZ, Provazníková I, Berger M, Bass C, Aratchige NS, López SN et al. (2019) Sex chromosome turnover in moths of the diverse superfamily Gelechioidea. Genome Biol Evol 11:1307-1319

Charlesworth D, Charlesworth B, Marais G (2005) Steps in the evolution of heteromorphic sex chromosomes. Heredity 95:118-128

Dalíková M, Zrzavá M, Hladová I, Nguyen P, Šonský I, Flegrová M et al. (2017a) New insights into the evolution of the W chromosome in Lepidoptera. J Hered 108:709-719

Dalíková M, Zrzavá M, Kubíčková S, Marec F (2017b) W-enriched satellite sequence in the Indian meal moth, Plodia interpunctella (Lepidoptera, Pyralidae). Chromosome Res 25:241-252

Dincă V, Lukhtanov VA, Talavera G, Vila R (2011) Unexpected layers of cryptic diversity in wood white Leptidea butterflies. Nat Commun 2:324

Dincă V, Wiklund C, Lukhtanov VA, Kodandaramaiah U, Norén K, Dapporto L et al. (2013) Reproductive isolation and patterns of genetic differentiation in a cryptic butterfly species complex. J Evol Biol 26:2095-2106

Dopman EB, Perez L, Bogdanowicz SM, Harrison RG (2005) Consequences of reproductive barriers for genealogical discordance in the European corn borer. Proc Natl Acad Sci USA 102:14706-14711

Ebersberger I, Strauss S, von Haeseler A (2009) HaMStR: profile hidden Markov model based search for orthologs in ESTs. BMC Evol Biol 9:157

Filatov DA (2018) The two "rules of speciation" in species with young sex chromosomes. Mol Ecol 27:3799-3810

Fraïsse C, Picard MAL, Vicoso B (2017) The deep conservation of the Lepidoptera $\mathrm{Z}$ chromosome suggests a non-canonical origin of the W. Nat Commun 8:1486

Friberg M, Vongvanich N, Borg-Karlson A-K, Kemp DJ, Merilaita S, Wiklund C (2008) Female mate choice determines reproductive isolation between sympatric butterflies. Behav Ecol Sociobiol 62:873-886

Fuková I, Traut W, Vítková M, Nguyen P, Kubíčková S, Marec F (2007) Probing the $\mathrm{W}$ chromosome of the codling moth, Cydia pomonella, with sequences from microdissected sex chromatin. Chromosoma 116:135-145

Gilbert D (2013) Gene-omes built from mRNA seq not genome DNA. 7th Annual Arthropod Genomics Symposium. Notre Dame. F1000Research 5:1695. https://doi.org/10.7490/f1000research. 1112594.1

Gotter AL, Levine JD, Reppert SM (1999) Sex-linked period genes in the silkmoth, Antheraea pernyi: implications for circadian clock regulation and the evolution of sex chromosomes. Neuron 24:953-965

Graves JAM (2016) Did sex chromosome turnover promote divergence of the major mammal groups? Bioessays 38:734-743 
Haas BJ, Papanicolaou A, Yassour M, Grabherr M, Blood PD, Bowden J et al. (2013) De novo transcript sequence reconstruction from RNA-seq using the Trinity platform for reference generation and analysis. Nat Protoc 8:1494-1512

Hill J, Rastas P, Hornett EA, Neethiraj R, Clark N, Morehouse N et al. (2019) Unprecedented reorganization of holocentric chromosomes provides insights into the enigma of lepidopteran chromosome evolution. Sci Adv 5:eaau3648

Kitano J, Peichel CL (2012) Turnover of sex chromosomes and speciation in fishes. Environ Biol Fishes 94:549-558

Kitano J, Ross JA, Mori S, Kume M, Jones FC, Chan YF et al. (2009) A role for a neo-sex chromosome in stickleback speciation. Nature 461:1079-1083

Kiuchi T, Koga H, Kawamoto M, Shoji K, Sakai H, Arai Y et al. (2014) A single female-specific piRNA is the primary determiner of sex in the silkworm. Nature 509:633-636

Kost S, Heckel DG, Yoshido A, Marec F, Groot AT (2016) A Z-linked sterility locus causes sexual abstinence in hybrid females and facilitates speciation in Spodoptera frugiperda. Evolution 70:1418-1427

Lukhtanov VA, Dincă V, Friberg M, Šíchová J, Olofsson M, Vila R et al. (2018) Versatility of multivalent orientation, inverted meiosis, and rescued fitness in holocentric chromosomal hybrids. Proc Natl Acad Sci USA 115:9610-9619

Lukhtanov VA, Dincă V, Talavera G, Vila R (2011) Unprecedented within-species chromosome number cline in the Wood White butterfly Leptidea sinapis and its significance for karyotype evolution and speciation. BMC Evol Biol 11:109

Mank JE, Hosken DJ, Wedell N (2014) Conflict on the sex chromosomes: cause, effect, and complexity. Cold Spring Harb Perspect Biol 6:a017715

Mank JE, Vicoso B, Berlin S, Charlesworth B (2010) Effective population size and the faster-X effect: empirical results and their interpretation. Evolution 64:663-674

Marec F, Sahara K, Traut W (2010) Rise and fall of the W chromosome in Lepidoptera. In: Goldsmith MR, Marec F (eds) Molecular biology and genetics of the Lepidoptera. CRC Press, Boca Raton, FL, USA, p 49-63

Moghadam HK, Pointer MA, Wright AE, Berlin S, Mank JE (2012) W chromosome expression responds to female-specific selection. Proc Natl Acad Sci USA 109:8207-8211

Mongue AJ, Nguyen P, Voleníková A, Walters JR (2017) Neo-sex chromosomes in the monarch butterfly, Danaus plexippus. G3 7:3281-3294

Naisbit RE, Jiggins CD, Linares M, Salazar C, Mallet J (2002) Hybrid sterility, Haldane's rule and speciation in Heliconius cydno and H. melpomene. Genetics 161:1517-1526

Nguyen P, Sýkorová M, Šíchová J, Kůta V, Dalíková M, Čapková Frydrychová R et al. (2013) Neo-sex chromosomes and adaptive potential in tortricid pests. Proc Natl Acad Sci USA 110:6931-6936

Pennell MW, Kirkpatrick M, Otto SP, Vamosi JC, Peichel CL, Valenzuela N et al. (2015) Y fuse? Sex chromosome fusions in fishes and reptiles. PLoS Genet 11:e1005237

Pfaffl MW (2001) A new mathematical model for relative quantification in real-time RT-PCR. Nucleic Acids Res 29:e45

Picq S, Lumley L, Šíchová J, Laroche J, Pouliot E, Brunet BMT et al. (2018) Insights into the structure of the spruce budworm (Choristoneura fumiferana) genome, as revealed by molecular cytogenetic analyses and a high-density linkage map. G3 8:2539-2549

Presgraves DC (2002) Patterns of postzygotic isolation in Lepidoptera. Evolution 56:1168-1183

Presgraves DC (2008) Sex chromosomes and speciation in Drosophila. Trends Genet 24:336-343

Pringle EG, Baxter SW, Webster CL, Papanicolaou A, Lee SF, Jiggins CD (2007) Synteny and chromosome evolution in the
Lepidoptera: evidence from mapping in Heliconius melpomene. Genetics 177:417-426

Qvarnström A, Bailey RI (2009) Speciation through evolution of sexlinked genes. Heredity 102:4-15

Rens W, Grützner F, O'Brien PCM, Fairclough H, Graves JAM, Ferguson-Smith MA (2004) Resolution and evolution of the duck-billed platypus karyotype with an $\mathrm{X}_{1} \mathrm{Y}_{1} \mathrm{X}_{2} \mathrm{Y}_{2} \mathrm{X}_{3} \mathrm{Y}_{3} \mathrm{X}_{4}$ $\mathrm{Y}_{4} \mathrm{X}_{5} \mathrm{Y}_{5}$ male sex chromosome constitution. Proc Natl Acad Sci USA 101:16257-16261

Šafář J, Šimková H, Kubaláková M, Č́íhalíková J, Suchánková P, Bartoš J et al. (2010) Development of chromosome-specific BAC resources for genomics of bread wheat. Cytogenet Genome Res 129:211-223

Sahara K, Yoshido A, Traut W (2012) Sex chromosome evolution in moths and butterflies. Chromosome Res 20:83-94

Šíchová J, Ohno M, Dincă V, Watanabe M, Sahara K, Marec F (2016) Fissions, fusions, and translocations shaped the karyotype and multiple sex chromosome constitution of the northeast-Asian wood white butterfly, Leptidea amurensis. Biol J Linn Soc 118:457-471

Š́chová J, Voleníková A, Dincă V, Nguyen P, Vila R, Sahara K et al. (2015) Dynamic karyotype evolution and unique sex determination systems in Leptidea wood white butterflies. BMC Evol Biol 15:89

Smith DAS, Gordon IJ, Traut W, Herren J, Collins S, Martins DJ et al. (2016) A neo-W chromosome in a tropical butterfly links colour pattern, male-killing, and speciation. Proc Biol Sci 283:20160821

Sperling FAH (1994) Sex-linked genes and species differences in Lepidoptera. Can Entomol 126:807-818

Sweigart AL (2010) Simple Y-autosomal incompatibilities cause hybrid male sterility in reciprocal cross between Drosophila virilis and D. americana. Genetics 184:779-787

Talla V, Johansson A, Dincă V, Vila R, Friberg M, Wiklund C et al. (2019a) Lack of gene flow: narrow and dispersed differentiation islands in a triplet of Leptidea butterfly species. Mol Ecol 28:3756-3770

Talla V, Soler L, Kawakami T, Dincă V, Vila R, Friberg M et al. (2019b) Dissecting the effects of selection and mutation on genetic diversity in three wood white (Leptidea) butterfly species. Genome Biol Evol 11:2875-2886

Talla V, Suh A, Kalsoom F, Dincă V, Vila R, Friberg M et al. (2017) Rapid increase in genome size as a consequence of transposable element hyperactivity in wood-white (Leptidea) butterflies. Genome Biol Evol 9:2491-2505

Traut W, Ahola V, Smith DAS, Gordon IJ, ffrench-Constant RH (2017) Karyotypes versus genomes: the nymphalid butterflies Melitaea cinxia, Danaus plexippus, and D. chrysippus. Cytogenet Genome Res 153:46-53

Traut W, Sahara K, Marec F (2007) Sex chromosomes and sex determination in Lepidoptera. Sex Dev 1:332-346

Turelli M, Begun DJ (1997) Haldane's rule and X-chromosome size in Drosophila. Genetics 147:1799-1815

Van't Hof AE, Nguyen P, Dalíková M, Edmonds N, Marec F, Saccheri IJ (2013) Linkage map of the peppered moth, Biston betularia (Lepidoptera, Geometridae): a model of industrial melanism. Heredity 110:283-295

Wadsworth CB, Li X, Dopman EB (2015) A recombination suppressor contributes to ecological speciation in OSTRINIA moths. Heredity 114:593-600

Wright AE, Dean R, Zimmer F, Mank JE (2016) How to make a sex chromosome. Nat Commun 7:12087

Yasukochi Y (2002) PCR-based screening for bacterial artificial chromosome libraries. Methods Mol Biol 192:401-410

Yasukochi Y, Ohno M, Shibata F, Jouraku A, Nakano R, Ishikawa Y et al. (2016) A FISH-based chromosome map for the European corn borer yields insights into ancient chromosomal fusions in the silkworm. Heredity 116:75-83 
Yasukochi Y, Tanaka-Okuyama M, Shibata F, Yoshido A, Marec F, $\mathrm{Wu} \mathrm{C}$ et al. (2009) Extensive conserved synteny of genes between the karyotypes of Manduca sexta and Bombyx mori revealed by BAC-FISH mapping. PLoS One 4:e7465

Yoshido A, Marec F, Sahara K (2016) The fate of W chromosomes in hybrids between wild silkmoths, Samia cynthia ssp.: no role in sex determination and reproduction. Heredity 116:424-433

Yoshido A, Sahara K, Marec F, Matsuda Y (2011a) Step-by-step evolution of neo-sex chromosomes in geographical populations of wild silkmoths, Samia cynthia ssp. Heredity106:614-624
Yoshido A, Sahara K, Yasukochi Y (2015) Silk moths (Lepidoptera). In: Sharakhov IV (ed) Protocols for cytogenetic mapping of arthropod genomes. CRC Press, Boca Raton, FL, USA, p 219-256

Yoshido A, Yasukochi Y, Sahara K (2011b) Samia cynthia versus Bombyx mori: comparative gene mapping between a species with a low-number karyotype and the model species of Lepidoptera. Insect Biochem Mol Biol 41:370-377

Xie Y, Wu G, Tang J, Luo R, Patterson J, Liu S et al. (2014) SOAPdenovo-Trans: de novo transcriptome assembly with short RNA-Seq reads. Bioinformatics 30:1660-1666 